\title{
Don't make me angry, you wouldn't like me when I'm angry: Volitional choices to act or inhibit are modulated by subliminal perception of emotional faces
}

\author{
Jim Parkinson ${ }^{1,2}$ • Sarah Garfinkel ${ }^{1,4}$ • Hugo Critchley ${ }^{1,4} \cdot$ Zoltan Dienes $^{1,2}$. \\ Anil K. Seth ${ }^{1,3}$
}

Published online: 5 December 2016

(C) The Author(s) 2016. This article is published with open access at Springerlink.com

\begin{abstract}
Volitional action and self-control-feelings of acting according to one's own intentions and in being control of one's own actions - are fundamental aspects of human conscious experience. However, it is unknown whether high-level cognitive control mechanisms are affected by socially salient but nonconscious emotional cues. In this study, we manipulated free choice decisions to act or withhold an action by subliminally presenting emotional faces: In a novel version of the Go/NoGo paradigm, participants made speeded button-press responses to Go targets, withheld responses to NoGo targets, and made spontaneous, free choices to execute or withhold the response for Choice targets. Before each target, we presented emotional faces, backwards masked to render them nonconscious. In Intentional trials, subliminal angry faces made participants more likely to voluntarily withhold the action, whereas fearful and happy faces had no effects. In a second experiment, the faces were made supraliminal, which eliminated the effects of angry faces on volitional choices. A third experiment measured neural correlates of the effects of subliminal angry faces on intentional choice using EEG. After replicating the behavioural results found in
\end{abstract}

Electronic supplementary material The online version of this article (doi:10.3758/s13415-016-0477-5) contains supplementary material, which is available to authorized users.

Jim Parkinson

j.m.parkinson@sussex.ac.uk

1 Sackler Centre for Consciousness Science, University of Sussex, Brighton, UK

2 School of Psychology, University of Sussex, Brighton, UK

3 Department of Informatics, University of Sussex, Brighton, UK

4 Brighton and Sussex Medical School, Brighton, UK
Experiment 1, we identified a frontal-midline theta component-associated with cognitive control processes - which is present for volitional decisions, and is modulated by subliminal angry faces. This suggests a mechanism whereby subliminally presented "threat" stimuli affect conscious control processes. In summary, nonconscious perception of angry faces increases choices to inhibit, and subliminal influences on volitional action are deep seated and ecologically embedded.

Keywords Cognitive control $\cdot$ Decision-making $\cdot$ Emotion · ERP · Priming

Healthy adult individuals experience volitional control over many of their actions. This notion is fundamental to most conceptions of morality and responsibility. Voluntary control allows the individual to implement reasoned and flexible goaloriented action rather than being constantly enslaved by automatic responses to the external environment (Shadlen \& Gold, 2004). While volitional production of actions has been long studied (e.g., Libet, Gleason, Wright, \& Pearl, 1983), not much attention has been given to volitional self-control and the role of inhibition in volition (but see Filevich, Kühn, \& Haggard, 2012; Parkinson \& Haggard, 2014, 2015).

Some forms of self-control can be considered tonic - or long lasting - such as refraining from a substance of abuse. This is often colloquially referred to as "willpower" (Baumeister, Bratslavsky, Muraven, \& Tice, 1998; Baumeister, Vohs, \& Tice, 2007). Other forms focus on more immediate and transient moments of self-control - the notion of "stopping oneself from doing something at the last moment"-which we call intentional inhibition (Filevich et al., 2012; Parkinson \& Haggard, 2014). As an everyday example, consider refraining from shouting at a loved one whilst in anger. Experimentally we define this as endogenously 
cancelling a currently planned action that has a strong associated urge or prepotency. This can be considered a form of volitional cognitive inhibitory control as the ability to choose to cancel an (possibly unhelpful) urge allows for more flexible cognition and behaviour (Diamond, 2013), demonstrating what Shadlen refers to as "freedom from immediacy" (Shadlen \& Gold, 2004).

It has been argued that such moments of volitional selfcontrol constitute high-level and effortful cognitive control processes that are intimately linked to conscious awareness (Dehaene et al., 2003; Hommel, 2007; Mayr, 2004). On these views, to consciously resist a prepotent action one should also be conscious of the urge to act, of the need to inhibit it, and subsequently of the volitional decision to do so. However, several studies have demonstrated nonconscious manipulation of motor-control processes via subliminal priming (e.g., van Gaal, Lamme, Fahrenfort, \& Ridderinkhof, 2011; van Gaal, Ridderinkhof, van den Wildenberg, \& Lamme, 2009). However, these studies focused on exogenously (stimuluselicited) inhibition, leaving open the question of whether there are nonconscious effects on volitional, endogenously generated intentional inhibition.

In a previous study, Parkinson and Haggard (2014) uncovered initial evidence that nonconscious information can influence supposedly "free" volitional decisions to act or inhibit. In a modified Go/NoGo task, participants prepared a unimanual button press and watched for visual targets (arrows). Commonly presented Reactive Go targets elicited speeded responses. Rare Reactive NoGo targets indicated that participants must inhibit the prepared response. Critically, a third set of Intentional Go trials required participants to make quick, spontaneous decisions whether to execute the button press or not (Intentional Go/NoGo). Thus, over the course of the experiment participants made both Intentional Go and NoGo responses, alongside their Reactive counterparts.

Prior to each target, arrow prime stimuli were presented subliminally using backwards masking. Some subliminal primes facilitated Reactive Go responses, indicated by speeded response times, whereas other primes were inhibitory, slowing Reactive Go responses. The key finding was that Intentional responses were affected by subliminal priming. As with Reactive Go responses, facilitatory primes speeded Intentional actions, whereas inhibitory primes slowed them. Subliminal primes also influenced the actual volitional choice participants made in Intentional Go trials: Following facilitatory primes, individuals were more likely to make the volitional decision to press the button, while inhibitory primes made them more likely to choose to withhold. Thus, this study showed that simple volitional decisions to withhold or execute an action could be manipulated by nonconscious means.

An important limitation in Parkinson and Haggard's (2014) study is that the observed subliminal priming effects were based on arbitrary stimulus-response mappings between target and response, and the effects of the subliminal primes on intentional inhibition can be attributed simply to visual congruency between prime and target stimuli, facilitating or inhibiting the appropriate response choice at a motor level (Eimer \& Schlaghecken, 2003). Thus, the mechanism underlying Parkinson and Haggard's (2014) effect may not lie at a high cognitive level, nor would this manipulation occur outside the realms of this specific experiment and stimulus set. This leaves open the important question of whether volitional self-control can be manipulated by ecologically valid and socially relevant stimuli (i.e., emotional human faces) for which salience for volition cannot be accounted for in terms of lowlevel properties of congruence or in congruence.

In this study we addressed the above question over the course of three experiments, using emotional human faces as stimuli. In Experiment 1 we adapted the Go/NoGo/Choose paradigm using coloured circles as target stimuli: green for Reactive Go, red for Reactive NoGo and yellow for Intentional Choice. Prior to each target, a subliminal emotional face prime - angry, happy, fearful, or neutral - was presented for a short duration (20 ms) and backwards masked using a scrambled face image (see Fig. 1). We examined the effects of subliminal emotional faces on volitional decisions made on Intentional Choice trials, and on response times. The subliminal nature of emotional face primes was verified by measuring $d$ ' in a short face present/absent detection task.

In Experiment 2, we used the same paradigm, but with increased presentation duration of the faces $(100 \mathrm{~ms})$ to investigate the effects of consciously perceived (supraliminal) emotional faces on volitional decisions.

Finally, in Experiment 3, we further investigated the effects of subliminal emotional faces (in this case, specifically anger compared to neutral only) on volitional self-control using electroencephalography (EEG). Specifically, we focused on two EEG correlates of self-control. The first is the negative going event-related potential (ERP) component known as the N2, known as an index of reactive stopping (e.g., in a typical Go/NoGo task; Pfefferbaum, Ford, Weller, \& Kopell, 1985), but which has also recently been linked to volitional decisions to execute or inhibit an action (Parkinson \& Haggard, 2015). The second is frontal-midline theta $(\mathrm{FM}-\theta)$ power, measuring oscillatory EEG activity in the 4-7 Hz range that has been interpreted as a signature of cognitive control (see Cavanagh \& Frank, 2014, for a review).

We selected human faces as subliminal/supraliminal primes for several reasons. Human faces are a privileged class of visual stimuli, with dedicated cognitive and neurological systems involved in processing facial identity and more transient properties of the face such as eye gaze, mouth movements, and facial expression (Bruce \& Young, 1986; Haxby, Hoffman, \& Gobbini, 2000). Facial expressions are of crucial importance in social interactions (see Frith, 2009, for a review): Emotional expressions allow an individual- 


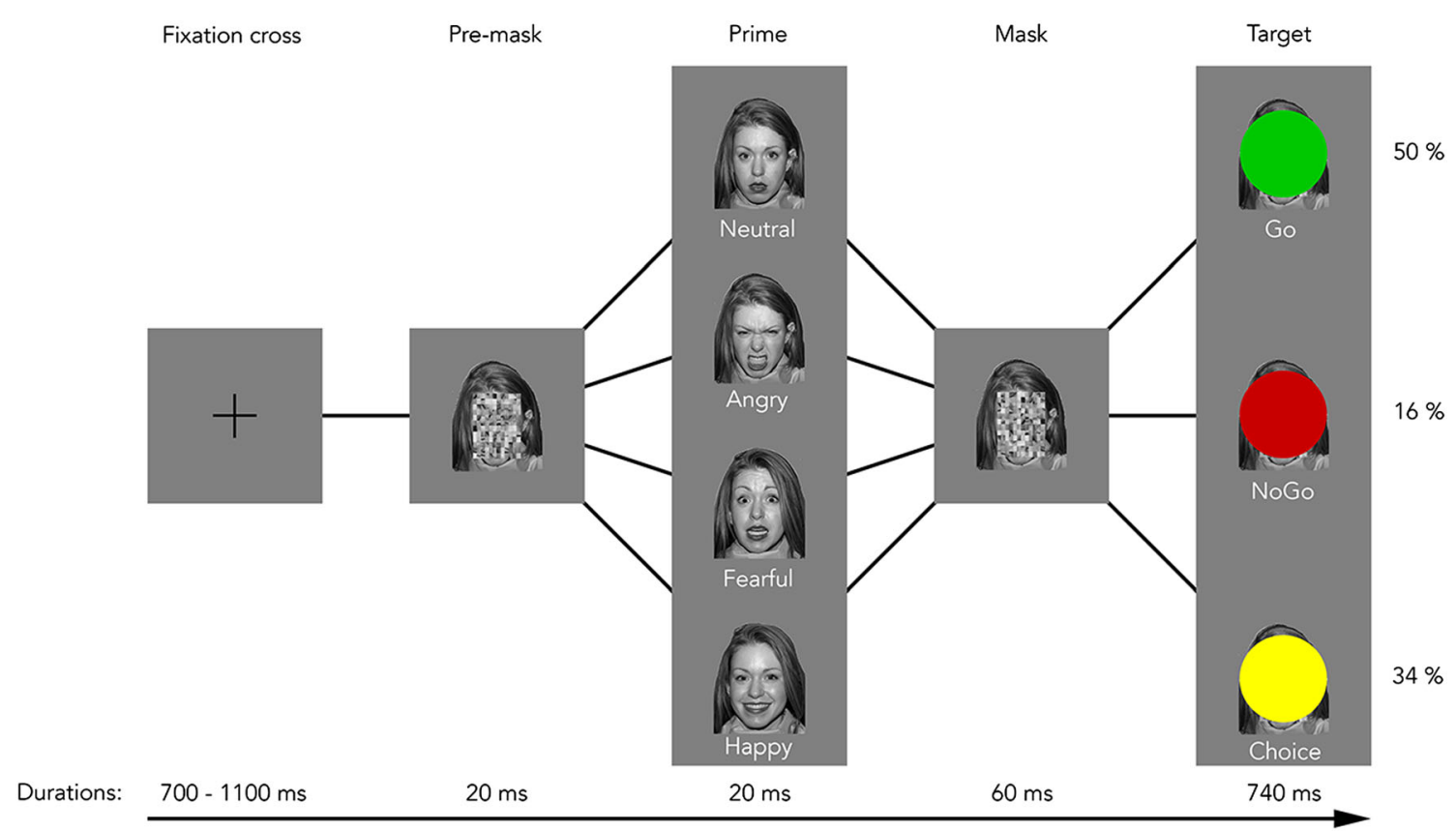

Fig. 1 Example stimulus sequences from Experiment 1. This figure shows examples of the four emotional subliminal face primes used in Experiment 1, represented by one example face identity. Experiment 2 used similar sequences except primes were presented for $100 \mathrm{~ms}$. Experiment 3 used same stimulus timings as Experiment 3, but only neutral and angry faces were used as primes. intentionally or not - to communicate not only her emotional state but also her social motives.

We reasoned that the different emotional primes would affect volitional choices to act or inhibit in different ways. Emotionally neutral faces were used as a baseline emotional prime with which to compare the effects of other emotions. Happy faces have been shown to elicit "approach" responses, decreasing response times when they are Go targets, and decreasing inhibitory ability (increasing errors of commission) when they are NoGo targets, as compared to sad faces (Schulz et al., 2007). We therefore predicted that subliminal happy faces would also elicit approach responses in participants and, specifically, would increase their volitional choices to act rather than inhibit in Choice trials. Fearful faces have been shown to increase response times, but not affect errors of commission in a stop-signal task (Sagaspe, Schwartz, \& Vuilleumier, 2011). This is in line with inhibitory, withdrawal effects evoked by fearful faces (Veling, Aarts, \& Stroebe, 2011); the subjective evocation of fear is known to suppress primary motor cortex activity (Nigg, Butler, HuangPollock, \& Henderson, 2002). We therefore predicted that subliminal fearful faces would increase participants' likelihood of choosing to intentionally inhibit their actions.

The effects of perceiving angry faces are more difficult to hypothesize. Emotional contagion (e.g., Harrison, Morgan, \& Critchley, 2010; Hatfield, Cacioppo, \& Rapson, 1993) would suggest that perceiving anger induces anger in the viewer, perhaps leading to an increase in impulsive, approach behaviours (e.g., Aarts et al., 2010). However, angry expressions on others can signify hostility (Lyman \& Averill, 1982; Yik, 1999), dominance (Hess, Adams, \& Kleck, 2009; Jenkins \& Ball, 2000 ), or that social rules or expectations have been contravened (Blair, 2003). Thus, perceiving an angry face could convey to the viewer that she should cease her current behaviour, a process known as response reversal (Blair \& Cipolotti, 2000; Blair, Morris, Frith, Perrett, \& Dolan, 1999; Marsh, Ambady, \& Kleck, 2005). This suggests that an angry face can act as an inhibitory cue, and rather than eliciting a mirror feeling of anger it instead causes a complementary emotion - that of fear or pacification. Because of these two competing accounts, we did not hypothesize a specific direction of any effects of subliminal angry faces on intentional inhibition.

In summary, Experiment 1 adapted the $\mathrm{Go} / \mathrm{NoGo} / \mathrm{Choose}$ paradigm by presenting subliminal neutral, happy, fearful, and angry faces to investigate how nonconscious, socially salient, and ecologically valid stimuli affect high-level volitional decisions to act or inhibit an action. Experiment 2 repeated this paradigm except using supraliminal emotional faces. Experiment 3 further investigated the effects from Experiment 1 by concurrently measuring electroencephalogram (EEG).

\section{Experiment 1}

\section{Participants}

Twelve participants took part in Experiment 1, who were recruited from the University of Sussex School of Psychology 
undergraduate participant pool and volunteered in return for course credits. Eight were female, and the mean age was 18.83 years $(S D=0.83)$. The University of Sussex ethics committee approved the experimental procedures.

\section{Stimuli and procedure}

Figure 1 shows a schematic of a single trial. The experiment was presented to the participants as a simple button-press task during which they would respond using the index finger of their dominant (right) hand using the keyboard space bar (hereafter referred to as a "button press" or "response"). Each trial started with a centrally presented fixation cross, indicating where participants should focus their eyes and that they should prepare to make a response. The participants' instruction was to respond to coloured circle target stimuli that would appear at the centre of the screen.

The majority ( $50 \%$ ) of trials were Go trials, indicated with green targets. In these trials, participants were instructed to always make speeded button-press responses. If participants did not respond within $740 \mathrm{~ms}$ of target onset, the screen would flash red, indicating an error; participants were instructed to avoid errors by responding quickly and always preparing a response during fixation. Because of this preparation and the abundance of Go trials, the button press response can be considered a prepotent response in this design. Successful responses made to these targets comprised the Reactive Go responses. Unsuccessful trials in which participants failed to make responses comprised Reactive misses.

A minority of the trials $(16 \%)$ were NoGo trials, indicated by a red target circle. In these, participants were instructed to withhold responses. Because of the prepotency of the buttonpress response, successful NoGo trials should involve effortful inhibitory processes (Logan \& Cowan, 1984; Verbruggen $\&$ Logan, 2008). Successful withholding of responses in these trials comprised Reactive NoGo trials, and unsuccessful withholding (in which participants erroneously made a response) comprised Reactive false alarms.

The remaining $34 \%$ of the trials culminated in Choice targets, indicated by yellow target circles. Participants were informed that upon presentation of a Choice target, they should make a quick, volitional decision about whether to make the button-press response or withhold it. They were informed, both in writing and repeated verbally by the experimenter (JP) during instruction and practice, that the decision as to whether to make or withhold a response in Choice trials is entirely free; there was no right or wrong "answer" in Choice trials; there was no reward or punishment based on their choice in a given trial; and nothing in the experiment changes as a result of making the choice to respond or withhold responses.

Participants were asked to not "prechoose" (i.e., think of a possible Choice response prior to such a target occurring) but rather to make a quick decision to press or not press only when they saw the yellow Choice target. Participants were nevertheless encouraged to remember that they had two options to choose from and to try to use both throughout the experiment. Choice trials in which participants made responses comprised Intentional Go trials; Choice trials in which participants withheld the response comprised Intentional NoGo trials. In this design, there are no Intentional misses or false alarms.

The crucial experimental manipulation involved the subliminal presentation of emotional faces prior to target circles. These faces displayed the emotions of happiness, sadness, fear, anger, or were neutral in emotion (see Fig. 1). Prime faces were presented very briefly (20-ms duration) and were forwards and backwards masked using "scrambled" face images that rendered the intact emotional face consciously imperceptible. Emotional face stimuli were selected from the NimStim Face Stimulus Set. ${ }^{1}$ Three male and three female models were selected from the set, all of which were Caucasian. The faces had open mouths with possibly visible teeth. The images were rendered in greyscale, and luminance was normalised across all images using the SHINE toolbox for MATLAB (Willenbockel et al., 2010). The face stimuli were then placed on the same luminance grey value used as the background for the main experiment. Participants were not informed of the existence of the face primes before or during the main experiment, but were asked simply to focus on their responses to the coloured circles.

Each trial started with centrally placed white fixation cross (subtending 0.25 degrees). Fixation time was jittered between $700 \mathrm{~ms}$ and $1,100 \mathrm{~ms}$ in $100 \mathrm{~ms}$ steps, with this value pseudorandomly varied across all trial conditions. Following fixation, the masked emotional-prime stimulus was presented, in a position randomly jittered from the central fixation point by a maximum of \pm 0.5 degrees vertically and horizontally. The target circle appeared centrally on the screen, superimposed over the mask $60 \mathrm{~ms}$ after the latter's onset. After the end of each response period (740-ms from target onset), the screen became blank for a fixed intertrial interval (ITI) of $700 \mathrm{~ms}$.

Scrambled mask images were created as follows: An area 1 degree by 1 degree of visual angle was selected which entirely covered the facial features of each face stimulus. This part of each face image was partitioned into a $12 \times 12$ grid. The positions of these parts were then randomised to create a scrambled face image. For each face stimulus, 10 instances of a scrambled mask were created at the start of each experimental run. On each trial, the premask and mask stimuli were chosen at random from the appropriate set of scrambled faces.

\footnotetext{
${ }^{1}$ Development of the MacBrain Face Stimulus Set was overseen by Nim Tottenham and supported by the John D. and Catherine T. MacArthur Foundation Research Network on Early Experience and Brain Development. Please contact Nim Tottenham at tott0006@ tc.umn.edu for more information concerning the stimulus set.
} 
The experiments took place in dimly lit rooms. Stimuli were presented on a PC running MATLAB (MathWorks) and the Psychophysics Toolbox Version 3 (Brainard, 1997; Kleiner et al., 2007). A twenty-two-inch cathode ray tube monitor running at $100 \mathrm{~Hz}$ refresh rate was used. Participants made responses via a low latency keyboard. The monitor was placed comfortably at eye-level, and average viewing distance was around $60 \mathrm{~cm}$.

Experiment 1 used a 4 (emotional prime) $\times 2$ (Reactive/ Intentional $) \times 3(\mathrm{Go} / \mathrm{NoGo} / \mathrm{Choice})$ design. The experiment consisted of 720 trials, and lasted 35-40 minutes. For each of the four emotional face primes conditions, 90 Go, 30 NoGo, and 60 Choice trials were presented. Trials were split up into 18 blocks of 40 trials, lasting around 2 minutes each, with mandatory 10 -second breaks in between, after which participants manually initiated the next block. After instructions (written and verbal) and prior to the main experiment, participants took part in a practice session of one block (40 trials), consisting, for each emotion prime, of five Go, one NoGo, and four Choice trials.

Following the main experiment phase, the participants were given a second set of instructions, which explained the basic rationale behind the main experiment, including the presence of the masked subliminal faces prior to each target (the only point at which they knew faces had been presented). An example sequence was presented pictorially as part of the written instructions. These instructions informed them that the "prime" faces were supposed to be unseen to the "conscious eye", and that the purpose of the main experiment was to investigate whether emotional faces would affect their reactions to the stimuli. The instructions also informed them about the short detection task that followed.

This detection task was designed as an objective method if verifying that the face primes were indeed subliminal (see Results for analysis criteria for this). Participants were presented with 96 trials with the same stimulus sequence as the main experiment, except all trials finished with a Choice target (yellow circle). There were 96 trials in total, four of each face identity and emotion. In half of the trials, the emotional face prime stimulus was present within the sequence. In the other half, the prime stimulus was presented with a version of the scrambled face stimulus which was different to the premask and mask versions. Thus, in prime-absent trials, three different scrambled faces were shown in quick succession. The order of present/absent trials was randomised. Participants were instructed to try to detect the presence of an intact face. They were instructed that if they could not make a confident decision, they should make a guess response. One second after the stimulus sequence finished, the words Present and Absent were presented, randomly allocated to the left and right of the screen. Participants made their response by pressing the left or right arrow keys appropriate to their decision. Participants were given as long as required to make the decision and were told that response times were not an issue during the detection task.

\section{Analysis of behavioural data}

The behavioural data from Experiment 1 were analysed using MATLAB and Statistics Toolbox Release 2014b (The MathWorks, Inc., Natick, MA, United States) using a combination of methods. Significance testing was performed using ANOVA and $t$ tests. Simple effects of fearful, happy, and angry emotional primes were calculated using neutralprimed trials as baseline values. Bayes factors $(B)$ were computed to assess the strength of evidence for a given effect. A $B$ of 3 or above indicates substantial evidence for the alternative over the null hypotheses (Jeffreys, 1939), whereas (by symmetry) $B<1 / 3$ indicate substantial evidence for the null hypothesis. Values of $B$ between roughly $1 / 3$ and 3 indicate that the evidence is insensitive at distinguishing between the null and alternative hypotheses (Dienes, 2014).

The Bayes factor $B$ is the amount by which the data are better predicted by $\mathrm{H} 1$ than $\mathrm{H} 0$. Thus, to calculate $B$, predicted effects sizes for $\mathrm{H} 1$ are needed, as estimated from previous research. For comparisons for which the direction of effect could be predicted, $B$ was calculated with the predicted effect size used as the standard deviation of a half normal distribution, notated as $B_{\mathrm{H}(0, S D)}$. For effects for which there is no predicted direction, a normal distribution was used, with an $\mathrm{SD}$ also equal to the predicted effect size, notated as $\mathrm{B}_{\mathrm{N}(0, \mathrm{SD})}$ (see Dienes, 2014).

In the analyses of response times and volitional choices, we used prior effect sizes from Parkinson and Haggard (2014), and we predicted that compared to neutral faces, happy faces would produce response approach, speeding response times and increasing volitional choice to act, whereas we predicted fearful faces would produce response withdrawal, resulting in the opposite effects, and Bayes factors for these effects were calculated using half normal distributions in the appropriate directions. Because of the ambiguous effects of angry faces, we made no prediction regarding the direction of effects of response times and intentional choice, and thus $B$ s were calculated using a normal distribution.

When analysing response times for Reactive and Intentional Go trials, median response times were calculated for each participant, for each emotional prime, and analysed using a $2 \times 4$ repeated-measures ANOVA. Bs for response times were computed using a predicted effect size of $30 \mathrm{~ms}$, a rounded average of effects on response times of facilitatory and inhibitory arrow primes as compared to neutral arrow primes in Parkinson and Haggard (2014). When analysing volitional choices, Intentional Go rates were calculated as the percentage of Intentional trials in which participants chose to execute rather than withhold the button-press response following a given emotional prime. $B$ s for Intentional Go rates 
were computed using a predicted effect size of $5 \%$, again taken from Parkinson and Haggard (2014).

$D$-prime ( $d$ ') values for the detection and/or discrimination tasks were calculated for each participant, as an objective measure of performance. These values were tested against a value of zero (chance detection/discrimination performance) using a $t$ test, and Bayes factors were also calculated. Whilst we acknowledge the recent position taken by Peters and Lau (2015) that all above-chance objective performance (i.e., any $d$ ' above zero) is accompanied by at least some degree of subjective awareness, we still sought a reasonable prior objective $d$ ' value to calculate $B$ in order to provide evidence for participants being unaware (or at least minimally aware) of face primes as opposed to being fully aware of them. Szczepanowski and Pessoa (2007) compared objective and subjective (confidence rating) measures of face detection and discrimination. From this study we estimated that an objective $d$ ' of 0.3 tends to correspond to the cusp of subjective visibility, and this value was used to calculate half-normal $B$ s for detection/discrimination tasks.

\section{Results}

\section{False alarm rates, miss rates, and Intentional Go rates}

Mean false alarm rate (Reactive NoGo trials in which participants erroneously made a response) was $5.94 \%(S D=5.99)$. Mean miss rate (Reactive Go trials in which participants erroneously failed to respond) was $1.20 \%(S D=1.71)$. Disregarding emotional face priming, mean overall rate of choosing Intentional Go responses in Choice trials was $62.86 \%(S D=11.38)$.

\section{Detection task}

There was evidence that detection performance was no better than chance (mean $\left.d^{\prime}=-0.06, S D=0.20\right), t(11)=-1.09, \mathrm{p}=$ $\left..300, B_{\mathrm{H}(0,0.3)}=0.10\right)$, suggesting that participants were unable to consciously detect the presence of face primes, at least according to the level of objective performance that could be expected if the subjective threshold had possibly been exceeded (Szczepanowski \& Pessoa, 2007). Again we acknowledge the possibility that participants may have some minimal subjective awareness of some faces (Peters \& Lau, 2015), but we argue that the evidence is strongly in favour of them being mostly unaware.

\section{Response times}

Group means of response times are shown for Reactive Go (see Fig. 2a) and Intentional Go (Fig. 2b) trials. There was evidence for a main effect of response source (Reactive vs. Intentional), $F(1,11)=28, p<.001, \eta^{2}=.72, B_{\mathrm{H}(0,30)}=$
23,332, with response times for Intentional Go trials (409 ms, $S D=43$ ) overall slower than those for Reactive Go trials $(349 \mathrm{~ms}, S D=30)$. This indicates a response time cost in making a volitional decision to act, which replicates previous findings (Parkinson \& Haggard, 2014, 2015). However, there was no significant main effect of emotional prime, $F(3,33)=$ $0.41, p=.748, \eta^{2}=0.04$, and no significant interaction, $F(3$, 33) $=0.50, p=.673, \eta^{2}=.04$.

The simple effects of emotional faces on response times are presented in Table 1. For Reactive Go responses, there was evidence that the emotional faces (happy, fearful, angry) had no effects on response times as compared to neutral faces. For Intentional Go responses, there was no evidence one way or the other for effects of emotional faces on response times.

\section{Intentional Go rates}

There was a significant main effect of emotional primes on Intentional Go rates, $F(3,33)=4.12, p=.014, \eta^{2}=0.27$ (see Fig. 3). Crucially, there was evidence for a difference between angry and neutral primes. $t(11)=3.48, p=.005$, Cohen's $d_{\mathrm{z}}=$ 1.01 , mean difference $=6.08 \%, S E M=1.71, B_{\mathrm{N}(0,5)}=73.23$, such that Intentional Go rates following angry primes were on average $6.1 \%$ lower than those following neutral primes. These results indicate that when participants are subliminally primed with angry emotional faces and then given a choice about whether or not to execute a prepared action, they are more likely to choose to withhold responses compared to situations when they are primed with neutral emotional expressions.

There was evidence for no effect of happy faces on Intentional Go rates, $t(11)=0.79 p=.445$, Cohen's $d_{\mathrm{z}}=$ 0.23 , mean difference $=1.78 \%, S E M=2.24, B_{\mathrm{H}(0,5)}=0.25$. There was also moderate evidence for no effect of fearful faces on Intentional Go rates, $t(11)=0.14, p=.889$, Cohen's $d_{\mathrm{z}}=$ 0.04 , mean difference $=0.23 \%, S E M=1.60, B_{\mathrm{H}(0,5)}=0.34$.

\section{Experiment 2}

Experiment 1 demonstrated that subliminal angry faces could influence individuals' volitional decisions, making them more likely to intentionally withhold rather than execute a prepared action. The importance of this finding lies in the observation that emotional cues that are task-irrelevant yet socially important can influence conscious decision making, even when they are nonconsciously perceived. This suggests that sometimes our conscious behaviour can be unconsciously affected by environmental influences relevant to social interactions with human conspecifics.

Experiment 2 investigated whether the findings of Experiment 1 can be replicated when the emotional faces are presented supraliminally. Whilst in some paradigms of 

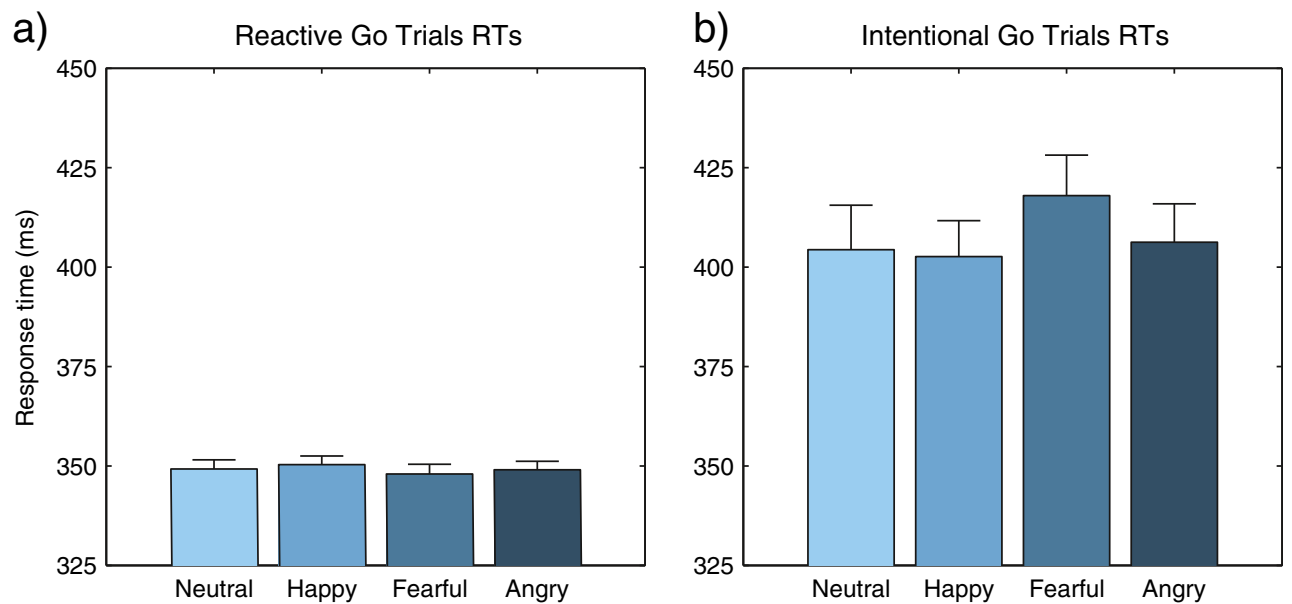

Fig. 2 Mean group response times in Experiment 1 for (a) Reactive Go trials and (b) Intentional Go trials. Error bars show within-subjects standard error following Cousineau-Morey corrections (Cousineau, 2005; Morey, 2008; O'Brien \& Cousineau, 2015). No statistically significant effects were found.

response priming, increasing subjective awareness of a prime increases its effect size (Atas, Vermeiren, \& Cleeremans, 2013), paradigms involving socially salient primes have suggested that conscious awareness of a prime can effectively eliminate priming effects (e.g., Sherman et al., 2009).

\section{Participants}

Twelve participants, who were recruited from the University of Sussex School of Psychology undergraduate participant pool and volunteered in return for course credits, took part in Experiment 2. None of the participants had taken part in Experiments 1 or 3 . Nine were female, and the mean age was 21.92 years $(S D=5.85)$. The University of Sussex ethics committee approved the experimental procedures.

\section{Stimuli and procedure}

Experiment 2 used the same procedure and stimuli as in Experiment 1, except that the prime faces were presented for $100 \mathrm{~ms}$ rather than $20 \mathrm{~ms}$, which rendered them clearly visible and their emotions discriminable. Following the main experiment, participants were debriefed, and a detection task (face present/absent) was performed as in Experiment 1, but again with the faces presented for $100 \mathrm{~ms}$. In addition to this, two discrimination tasks were performed using the stimuli from the experiment, in order to ascertain that participants could consciously parse the emotions of the faces: The first asked participants to discriminate between angry and neutral faces, the second between happy and fearful faces.

\section{Results}

False alarm rates, miss rates, and Intentional Go rates

Mean false alarm rate was $4.76 \%(S D=3.89)$. Mean miss rate was $1.78 \%(S D=1.95)$. Disregarding emotional face priming, mean overall rate of choosing Intentional Go responses in Choice trials was $57.86 \%(S D=8.78)$.

\section{Detection and discrimination tasks}

As expected, both the detection and discrimination tasks were easy, with participants often performing at ceiling. In these

Table 1 Simple effects of response times in Experiment 1, showing t test and Bayes factor results

\begin{tabular}{|c|c|c|c|c|c|c|c|}
\hline Emotional face effect & Mean difference (ms) & SEM & $t$ & $p$ & Cohen's $d_{\mathrm{z}}$ & Bayes factor & \\
\hline \multicolumn{8}{|l|}{ Reactive Go responses } \\
\hline Neutral-happy & -1.10 & 3.03 & -0.36 & 0.724 & -0.11 & $B_{\mathrm{H}(0,30)}$ & $=0.08$ \\
\hline Neutral-fearful & 1.25 & 3.13 & 0.40 & 0.696 & 0.12 & $B_{\mathrm{H}(0,30)}$ & $=0.08$ \\
\hline Neutral-angry & 0.21 & 3.48 & 0.06 & 0.953 & 0.02 & $B_{\mathrm{N}(0,30)}$ & $=0.12$ \\
\hline \multicolumn{8}{|c|}{ Intentional Go responses } \\
\hline Neutral-happy & 1.73 & 14.40 & 0.12 & 0.906 & 0.04 & $B_{\mathrm{H}(0,30)}$ & $=0.48$ \\
\hline Neutral-fearful & -13.60 & 16.02 & -0.85 & 0.414 & -0.25 & $B_{\mathrm{H}(0,30)}$ & $=0.97$ \\
\hline Neutral-angry & -1.89 & 14.64 & -0.13 & 0.900 & -0.04 & $B_{\mathrm{N}(0,30)}$ & $=0.44$ \\
\hline
\end{tabular}




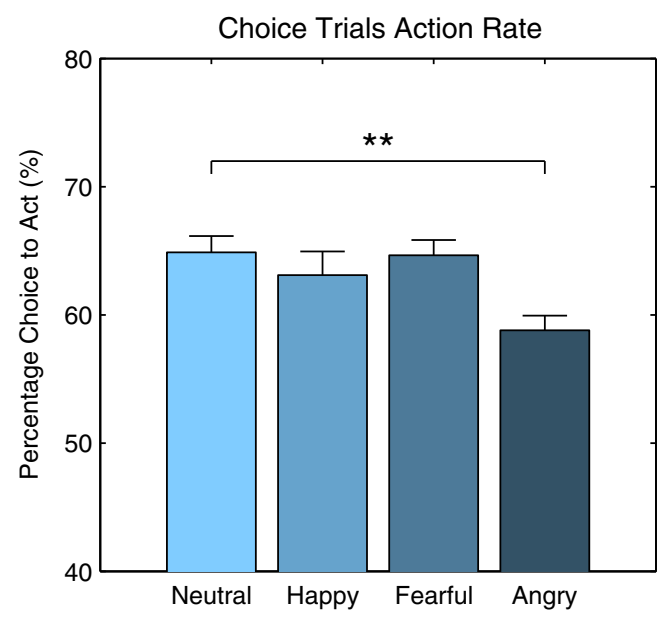

Fig. 3 Intentional Choice rate (mean rate at which participants chose to perform an action in Choice trials) in Experiment 1, according to the emotional face prime. Error bars show within-subjects standard error following Cousineau-Morey corrections. Stars indicate results of $t$ test comparison. $* * p<.01$. No stars indicates nonsignificant comparison

cases, hit rate was set to $99 \%$ (and false alarm rate to $1 \%$ ) to avoid infinite $d$ ' values. There was strong evidence that participants could easily detect the presence or absence of faces $\left(\right.$ mean $\left.d^{\prime}=4.39, S D=0.19\right), t(11)=78.52, p<.001, B_{\mathrm{H}(0,0.3)}=$ $\infty$, and discriminate between emotions (angry/neutral: mean $d$ ' $=3.91, S D=0.70), t(11)=19.39, p<.001, B_{\mathrm{H}(0,0.3)}>10^{10}$; (happy/fearful: mean $d^{\prime}=4.14, S D=0.66$ ), $t(11)=21.97, p<$ $.001, B_{\mathrm{H}(0,0.3)}>10^{10}$.

\section{Response times}

Response times were analysed as in Experiment 1. There was a significant main effect of response source (Reactive vs. Intentional), $F(1,11)=12.96, p=.004, \eta^{2}=0.54, B_{\mathrm{H}(0,30)}=$ 142 , with Intentional Go response times ( $405 \mathrm{~ms}, S D=56.78$ ) slower than those for Reactive Go trials ( $353 \mathrm{~ms}, S D=33.43$ ), replicating the findings from Experiment 1. There was no significant main effect of emotional prime, $F(3,33)=1.04$, $p=.389, \eta^{2}=0.09$, nor a significant interaction, $F(3,33)=$ $0.58, p=.604, \eta^{2}=0.05$.

The simple effects of emotional faces on response times are presented in Table 2. There was evidence for no effect of fearful and angry faces on both Reactive and Intentional response times, and no evidence either way for the effects of happy faces.

\section{Intentional Go rates}

Intentional Go rates were analysed as in Experiment 1. There was no significant main effect of emotional primes on Intentional Go rates, $F(3,33)=1.29, p=.294, \eta^{2}=0.11$. There was evidence for no effect of happy faces on Intentional Go rate, $t(11)=1.83, p=.094$, Cohen's $d_{\mathrm{z}}=$
0.53 , mean difference $=4.41 \%, \mathrm{SEM}=2.41, B_{\mathrm{H}(0.5)}=0.17$, with any difference here in the opposite direction to that predicted. There was no evidence one way or the other for the effects of fearful primes, $t(11)=1.17, p=.268$, Cohen's $d_{z}=$ 0.34 , mean difference $=3.03 \%, S E M=2.60, B_{\mathrm{H}(0,5)}=1.34$. For angry primes there was moderate evidence for no effect, $t(11)=0.232, p=.821$, Cohen's $d_{\mathrm{z}}=0.07$, mean difference $=$ $0.43 \%, S E M=1.83, B_{\mathrm{N}(0,5)}=0.41$.

\section{Summary}

The results from Experiment 1 provided evidence that subliminally presented angry faces reduce Intentional Go rates. There was no evidence that subliminal happy or fearful faces had such an effect. It is the effect of the subliminal angry faces we consider most critical result: Plausibly, they act like a nonconscious threat or withdrawal cue which can affect volitional, conscious decisions about whether to execute or intentionally inhibit an action. Conversely, in Experiment 2, there was moderate evidence that supraliminally presented emotional faces had no effects on Intentional Go rates (directly compare the scale of evidence for this effect in Experiment $1, B_{\mathrm{N}(0,5)}=$ 73.23 , with that in Experiment 2, $\left.B_{\mathrm{N}(0,5)}=0.41\right)$. Taken together, our findings indicate that in our paradigm the inhibitory effects of angry faces on conscious decisions are only present when one is not consciously aware of the angry faces. One possible explanation for this effect is that consciously perceived faces can be discounted as task irrelevant in virtue of a general functional flexibility afforded to consciously perceived stimuli (see also Discussion).

\section{Experiment 3}

Experiments 1 and 2 found that subliminally (but not supraliminally) presented angry faces can alter volition decisions to withhold a prepotent response. In Experiment 3, we examined the neural underpinnings of these effects of subliminal angry faces using EEG. To increase statistical power, we used only neutral and angry faces in this experiment. There were two a priori EEG effects of interest, which will be explained in detail below: First, we aimed to measure differences in the event-related potential (ERP) known as the N2 component. Second, we analysed differences in EEG frequency power over the course of a trial between different conditions, specifically looking at power changes in the theta band $(4-7 \mathrm{~Hz})$ over frontal-midline areas of the head.

\section{N2 ERP component}

Previous EEG studies of Go/NoGo tasks have mainly focused on the negative going ERP component known as N2, which is most prominent when measured at frontal-central electrodes, 
Table 2 Simple effects of response times in Experiment 2, showing t test and Bayes factor results

\begin{tabular}{|c|c|c|c|c|c|c|c|}
\hline Emotional face effect & Mean difference (ms) & SEM & $t$ & $p$ & Cohen's $d_{\mathrm{z}}$ & Bayes factor & \\
\hline \multicolumn{8}{|l|}{ Reactive Go responses } \\
\hline Neutral-happy & 3.39 & 1.68 & 2.02 & 0.069 & 0.58 & $B_{\mathrm{H}(0,30)}$ & $=0.83$ \\
\hline Neutral-fearful & 0.08 & 2.31 & 0.04 & 0.972 & 0.01 & $B_{\mathrm{H}(0,30)}$ & $=0.08$ \\
\hline Neutral-angry & 0.35 & 1.93 & 0.18 & 0.859 & 0.05 & $B_{\mathrm{N}(0,30)}$ & $=0.07$ \\
\hline \multicolumn{8}{|c|}{ Intentional Go responses } \\
\hline Neutral-happy & 4.17 & 6.97 & 0.60 & 0.562 & 0.17 & $B_{\mathrm{H}(0,30)}$ & $=0.39$ \\
\hline Neutral-fearful & 8.52 & 4.93 & 1.73 & 0.112 & 0.50 & $B_{\mathrm{H}(0,30)}$ & $=0.06$ \\
\hline Neutral-angry & -1.17 & 8.02 & -0.15 & 0.887 & -0.04 & $B_{\mathrm{N}(0,30)}$ & $=0.26$ \\
\hline
\end{tabular}

and peaks around 150-250 ms following the onset of the $\mathrm{Go} /$ NoGo target stimulus (Pfefferbaum et al., 1985). In general, larger (more negative) N2 components are observed following NoGo as compared to Go trials (Pfefferbaum et al., 1985), possibly reflecting effortful motor inhibition of the prepotent Go response (Bokura, Yamaguchi, \& Kobayashi, 2001; Eimer, 1993; Falkenstein, Hoormann, \& Hohnsbein, 1999; Lavric, Pizzagalli, \& Forstmeier, 2004; Pfefferbaum et al., 1985; van Gaal et al., 2011).

How might the $\mathrm{N} 2$ component behave in the Intentional Go trials in the present paradigm? In a previous study using a basic Go/NoGo/Choose paradigm, but without the presentation of any form of subliminal primes, we found that peak N2 amplitude, in both Intentional Go and Intentional NoGo trials, was as large as that for a Reactive NoGo trial, and higher than in Reactive Go trials (Parkinson \& Haggard, 2015). The presence of a strong N2 for Intentional trials suggests that the process of making a volitional decision to execute or withhold an action can entail initial inhibition of the prepotent Reactive response to allow for the Intentional decision. Therefore, in the current study we aimed to investigate whether subliminal angry faces, already shown to affect Intentional Go rates behaviourally (see Experiment 1), also affect the N2 ERP component. That is, does an angry subliminal face modulate the N2 component and can this account for its influence on Intentional Go rates?

\section{Frontal-midline theta band power}

Recent investigations of cognitive control and inhibition have also focused on ongoing changes in the oscillatory EEG, as measured by using time-frequency analysis. Here, we focus on the theta band (4-7 Hz) occurring over frontal-midline scalp areas. This frontal-midline theta $(\mathrm{FM}-\theta)$ has been associated with a variety of higher-level cognitive functions including novelty detection, working memory and top-down control (see Cavanagh \& Frank, 2014, for a review). It may even be that common ERP components that are observed in
EEG data recorded during these tasks reflect underlying changes in FM- $\theta$ synchronicity (Cavanagh \& Frank, 2014).

Previous studies have found increases in FM- $\theta$ power evoked by NoGo stimuli in a standard Go/NoGo paradigm (Cavanagh, Zambrano-Vazquez, \& Allen, 2012; KirmiziAlsan et al., 2006). These increases have been interpreted as reflecting internal response-conflict between a prepotent Go responses and the required withholding of that response. Based on this interpretation, we hypothesized that FM- $\theta$ will be higher for Reactive NoGo compared to Reactive Go trials (cf. Kirmizi-Alsan et al., 2006), and that intentional trials (both Go and NoGo) will also lead to increased FM- $\theta$, due to the involvement of response conflict, as mentioned above. Based on the results of Experiment 1, we further hypothesized that subliminal angry primes will lead to reduced FM- $\theta$, as compared to neutral primes, reflecting reduced response conflict.

\section{Participants}

Nineteen participants took part in Experiment 3, recruited from the University of Sussex School of Psychology undergraduate participant pool. Fifteen participants were paid $£ 20$ to take part, whilst four took part for course credits at their own request. None of these participants had taken part in Experiments 1 or 2. Three participants' data had to be rejected because of errors (recording errors or irrecoverably noisy EEG data). Of the remaining 16 participants, 10 were female and the mean age was 19.69 years $(S D=1.58)$.

\section{Stimuli and procedure}

The experimental paradigm was the same as Experiment 1, except that only neutral and angry face primes were presented. The experiment consisted of 720 trials, 360 of each emotional face prime. Of each set of 360, 180 were Reactive Go trials, 60 were Reactive NoGo, and 120 were Intentional Go trials. EEG was recorded at a sampling rate of $2048 \mathrm{~Hz}$ using a 64-channel Refa 8 amplifier and a 64-channel Waveguard EEG cap (both from ANT Neuro, Enschede, The Netherlands). External 
bipolar electrodes were attached above and below the left eye to obtain vertical electrooculogram (EOG), and on the left and right canthi to take horizontal EOG. The experiment was performed in a shielded Faraday cage.

Stimulus timings were identical to those in Experiment 1, with the exception of an additional 1,000-ms period following the response period during which the word BLINK was presented at the centre of the screen. Participants were given the same instructions as in Experiment 1, with the addition that they were instructed to not deviate their eyes from the fixation point and to refrain from blinking for the whole duration of the trial. They were asked to only blink during the period denoted by the word BLINK appearing on the screen. The purpose of this was to reduce artefacts produced by eye blinks and movements distorting trial-relevant EEG signals.

There was a similar debrief procedure as in Experiment 1 in which participants were informed of the presence of the primes. Again, they were asked to complete both a 96-trial prime detection task and a 96-trial prime discrimination task (in which face primes were always present, and participants had to make un-speeded "angry/neutral" judgements).

\section{Results}

\section{False alarm rates, miss rates, and Intentional Go rates}

Mean false alarm rate was $5.46 \%(S D=6.1)$. Mean miss rate was $2.90 \%(S D=2.59)$. Disregarding emotional face priming, mean overall rate of Intentional Go trials was $59.06 \%$ $(S D=8.30)$.

\section{Prime detection and discrimination tasks}

Detection and discrimination results were analysed as in Experiment 1. There was no evidence in either direction about whether prime detection performance was above chance (mean $\left.d^{\prime}=0.08, S D=0.19\right), t(15)=1.72, p=.107, B_{\mathrm{H}(0,0.3)}$ $=1.21$, so we cannot categorically state that participants were not able to detect the presence or absence of face primes, but the low magnitude of $d$ ' suggests that it was nevertheless difficult to do so. There was evidence that performance at the discrimination task was at chance (mean $d^{\prime}=0.03, S D=0.17$ ), $t(15)=0.62, p=.548, B_{\mathrm{H}(0,0.3)}=0.25$. Thus participants could not discriminate the emotion of the faces.

\section{Response times}

Response times were analysed as in Experiment 1. There was evidence for a main effect of response source (Reactive vs. Intentional), $F(1,15)=8.98, p=.009, \eta^{2}=0.37$, mean difference $=32.39 \mathrm{~ms}, S E M=10.58, B_{\mathrm{H}(0,30)}=42.83$, with Intentional Go response times ( $419 \mathrm{~ms}, S D=48.24)$ slower than those for Reactive Go trials ( $387 \mathrm{~ms}, S D=32.52)$, replicating the findings from Experiment 1.

There was evidence for no main effect of emotional prime on response times, $F(1,15)=1.07, p=.316, \eta^{2}=0.07$, mean difference $=3.41 \mathrm{~ms}, S E M=3.29, B_{\mathrm{N}(0,30)}=0.06$, and evidence for no interaction between emotional prime and response source, $F(1,16)=0.066, p=.801, \eta^{2}<.01$, interaction difference $=1.20 \mathrm{~ms}, S E M=4.80, B_{\mathrm{N}(0,30)}=0.16$.

There was evidence for no simple effects of angry faces on both Reactive and Intentional response times as compared to neutral faces, Reactive Go (mean difference $=2.8 \mathrm{~ms}, S E M=$ 2.43), $t(15)=1.15, p=.269$, Cohen's $d_{\mathrm{z}}=0.29, B_{\mathrm{N}(0,30)}=$ 0.16 ; Intentional Go (mean difference $=4.03 \mathrm{~ms}, S E M=$ 5.22), $t(15)=0.77, p=.453$, Cohen's $d_{\mathrm{z}}=0.19, B_{\mathrm{N}(0,30)}=$ 0.23 .

\section{Intentional Go rates}

Intentional Go rates were analysed as in Experiment 1. There was evidence for a main effect of angry primes on Intentional Go rates, $t(15)=2.67, p=.018$, Cohen's $d_{\mathrm{z}}=0.67, B_{\mathrm{N}(0,5)}=$ 7.37 , such that Intentional Go rates following angry primes were on average $3.78 \%$ lower than those following neutral primes, again replicating the findings from Experiment 1.

\section{EEG preprocessing}

EEG data was preprocessed using the FieldTrip software toolbox for MATLAB (Oostenveld, Fries, Maris, \& Schoffelen, 2011). Data were epoched according to trials by time locking to the onset of the target stimulus. To reject data potentially affected by eye movement or blink artefacts, signals from vertical EOG electrodes were filtered using a two-pass finite impulse response (FIR) band-pass filter between 1 and $15 \mathrm{~Hz}$, and then examined for signals that exceeded a $\pm 100 \mu \mathrm{V}$ threshold. EOG signals exceeding this threshold were marked as potential ocular artefacts, and any trials during which such artefacts occurred between -100 and 600 ms relative to target onset were excluded from further analysis.

For ERP/amplitude analysis, EEG data were filtered using a two-pass FIR band-pass filter between 0.1 and $40 \mathrm{~Hz}$ (following Lavric et al., 2004), with an additional discrete Fourier transform filter to remove electrical line noise (at 50, 100 , and $150 \mathrm{~Hz}$ ). Two-pass filtering was used to correct for the phase-shifting effects of filters, resulting in zero-phase filtering. Data were rereferenced to linked mastoids and base-lined over the period -200 to $-100 \mathrm{~ms}$ relative to target onset. This period was chosen to avoid the removal of EEG activity evoked by the prime stimuli. The data were then resampled to $256 \mathrm{~Hz}$.

For time-frequency analysis, EEG data were not subject to band-pass filtering with the exception of the DFT filter used to remove electrical line noise and the use of the FieldTrip 
detrending function to remove linear trends from the data. Data were again rereferenced to linked mastoids and resampled to $256 \mathrm{~Hz}$. For each participant, time-frequency power spectra were extracted from each individual trial of EEG data using a multitaper wavelet convolution method implemented in FieldTrip. Data were analysed from $-1,000$ to $700 \mathrm{~ms}$ relative to target onset, in 10-ms steps. Frequencies between 1 and $50 \mathrm{~Hz}$ were analysed in $0.5-\mathrm{Hz}$ steps. A Hanning taper was used, and the time length of the sliding window was set to span four cycles of the analysed frequency. After time-frequency analysis was complete, total power for each condition for each participant was computed by averaging power spectra across the appropriate trials. The length of each epoch was reduced to span -100 to +700 ms relative to target onset.

\section{ERP results}

For each participant, trial EEG data were averaged according to response source (Reactive vs. Intentional), response (Go vs. NoGo), and emotional prime (neutral vs. angry). Given our a priori focus on the N2 component, the ERP analysis was conducted on averaged EEG signals at five midline electrodes covering frontal-central to slightly behind vertex scalp areas (Fz, FCz, Cz, CPz, Pz; Pfefferbaum et al., 1985). Within each participant, the N2 component was identified separately within each condition of the $5 \times 2 \times 2 \times 2$ design by identifying the largest magnitude negative peak in the period between 50 and $300 \mathrm{~ms}$ relative to target onset. Peak latency for each condition was defined as the time point of this peak relative to target onset. Peak amplitude was defined as the amplitude (in $\mu \mathrm{V}$ ) of this peak. Note that because the N2 is defined as a negative going component, we consistently use terms regarding the "magnitude" of the N2 component as describing whether it is more or less negative in potential (more or less negative $\mu \mathrm{V})$.

Peak amplitudes and latencies were analysed using a $5 \times 2$ $\times 2 \times 2$ repeated-measures ANOVA. Bayes factors for simple effects were calculated based on ERP effects found in a previous experiment that replicated the arrow priming experiment of Parkinson and Haggard (2014) using EEG (Parkinson \& Haggard, 2015). In the latter experiment, significant peak amplitude differences were in the order of $4 \mu \mathrm{V}$, and those of peak latencies $40 \mathrm{~ms}$. Because directions of effects could not be predicted in all cases, $B$ s were conducted using a normal distribution.

Peak amplitudes Figure 4 shows grand average ERPs at representative frontal-central electrode $\mathrm{FCz}$, showing conditions Reactive/Intention $\times$ Go/NoGo. For peak amplitudes, there was evidence for no main effect of emotional prime (neutral vs. angry), $F(1,15)=0.10, p=.762, \eta^{2}=0.01$, mean difference $=0.10 \mu \mathrm{V}, S E M=0.22, B_{\mathrm{N}(0,4)}=0.08$. There was evidence for a main effect of response (Go vs. NoGo), $F(1$, $15)=9.37, p=.008, \eta^{2}=0.38, B_{\mathrm{N}(0,4)}=8.07$, such that peak amplitudes for NoGo responses $(M=-11.67, S D=4.24)$ were larger than those for Go responses $(M=-10.73, S D=4.31$, mean difference $=-0.94 \mu \mathrm{V}, S E M=0.22$ ). There was no evidence either way for a main effect of Response source (Reactive vs. Intentional), $F(1,15)=6.11, p=.026, \eta^{2}=$ $0.29, B_{\mathrm{N}(0,4)}=1.86$. However there was a significant main effect of electrode, $F(4,60)=30.14, p<.001, \eta^{2}=0.67$, such that $\mathrm{N} 2$ magnitude was overall greater at frontal-central electrodes $(\mathrm{Fz}, \mathrm{FCz}, \mathrm{Cz})$ than at more posterior sites $(\mathrm{CPz}, \mathrm{Pz})$. Moreover, there was a significant interaction between the factors of electrode and response source, $F(4,60)=4.57, p=$ $.017, \eta^{2}=0.23$. At frontal-central electrodes, there was evidence that intentional trials elicited larger N2 components than did reactive trials, whereas there was no evidence for this effect at more posterior sites (see Supplementary Table 1 for complete ANOVA results for peak amplitudes). To highlight, for N2 ERP amplitudes, there were no effects of emotional face prime.

Peak latencies For peak latencies, there was no significant main effect of electrode, $F(4,60)=0.19, p=.709, \eta^{2}=$ 0.01 . There was evidence for no main effects of either emotion, $F(1,15)=0.13, p=.296, \eta^{2}=0.01$, mean difference = $0.96 \mathrm{~ms}, S E M=2.73, B_{\mathrm{N}(0,40)}=0.07$, or response (Go vs. NoGo), $F(1,15)=0.08, p=.777, \eta^{2}=0.01$, mean difference $=-0.60 \mathrm{~ms}, S E M=2.07, B_{\mathrm{N}(0,40)}=0.05$. The main effect of Response source (Reactive vs. intentional) on peak latencies was significant, $F(1,15)=7.06, p=.018, \eta^{2}=0.32$, mean difference $=-7.87 \mathrm{~ms}, S E M=2.96, B_{\mathrm{N}(0,4)}=2.47$, such that N2 peaked earlier in Intentional compared to Reactive trials, but the evidence did not distinguish between the null and alternative hypotheses. No interactions were significant (see Supplementary Table 2 for complete ANOVA results for peak latencies).

\section{ERP summary}

The results show that overall N2 magnitude was larger at frontal-central electrode sites as compared to more posterior areas, which was to be expected (Pfefferbaum et al., 1985). Importantly, N2 magnitudes were larger for NoGo trials than Go trials, suggesting that overall, the process of selecting a NoGo response rather than a Go response requires effortful response inhibition. At frontal-central sites, N2 magnitude was also larger-and somewhat earlier-for Intentional compared to Reactive trials, indicating that making a volitional decision about one's response, as opposed to reacting to an external cue, entails more motor inhibition and/or response conflict overall. Crucially, N2 magnitudes were not modulated by subliminal emotional primes (angry vs. neutral faces). 

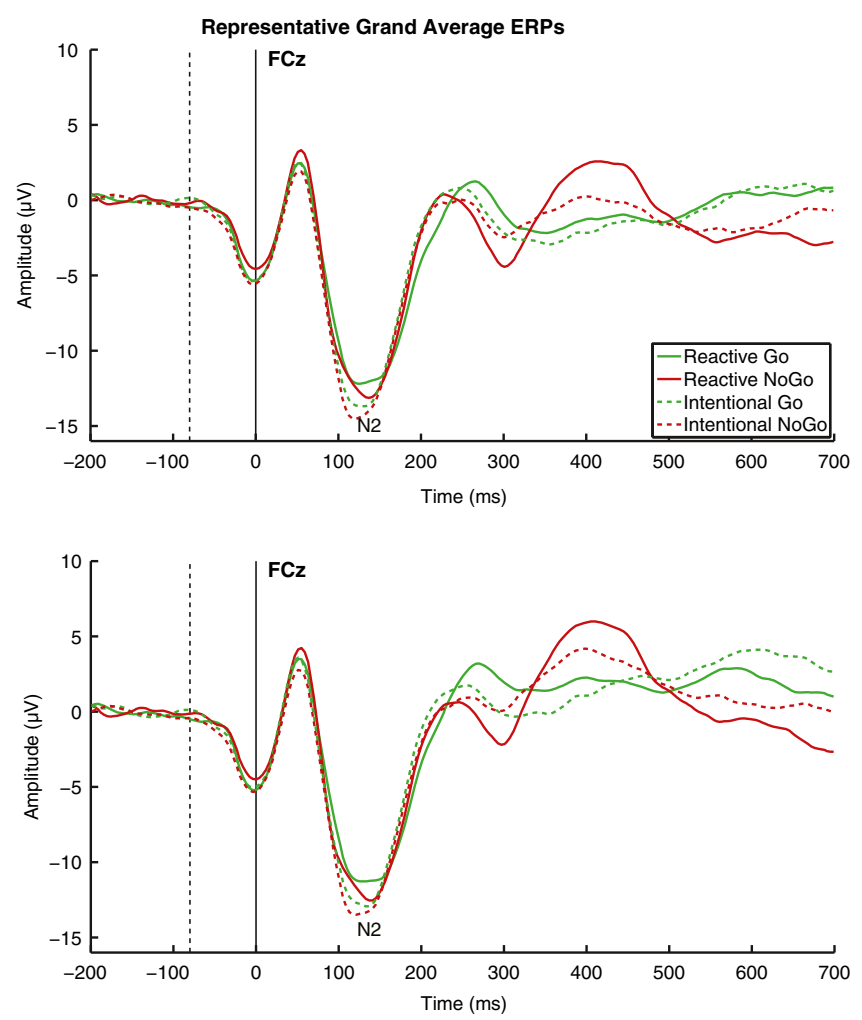

Fig. 4 Grand average ERP waveforms from representative frontalcentral channels $\mathrm{Fz}, \mathrm{FCz}$, and $\mathrm{Cz}$, showing the Reactive/Intentional $\times$ Go/NoGo conditions, with the N2 component labelled. The solid vertical

\section{Frontal-midline theta power analysis}

For each participant and each condition, mean power spectra were computed for the frequency band of interest, the theta band (4-7 Hz), over the period from target onset until $500 \mathrm{~ms}$ after target onset, over frontal-midline electrodes $(\mathrm{Cz}$ and $\mathrm{FCz}$ ). These values were analysed using a 2 (Reactive vs. Intentional) $\times 2$ (Go vs. NoGo) $\times 2$ (Neutral vs. Angry emotional prime) repeated-measures ANOVA (see Supplementary Table 3 for full ANOVA results). Simple effects were tested with $t$ tests, and Bayes factors were computed using a distribution with a mean of zero and a standard deviation of $2 \mu \mathrm{V}^{2}$, the latter value estimated from example theta changes seen in Cavanagh and Frank's (2014) review of cognitive control effects of theta (note that it was not possible to predict effects of priming on theta power, so this estimate may be conservative).

We found evidence for two 2-way interactions. The first was between Response Source and Response, $F(1,15)=8.70$, $p=.010, \eta^{2}=0.37$, interaction difference $=2.40 \mu \mathrm{V}^{2}, S E M=$ $0.82, B_{\mathrm{N}(0,2)}=14.80$, shown in Fig. 5. Simple tests reveal that for Reactive responses, FM- $\theta$ was significantly larger for Reactive NoGo responses $\left(M=4.46 \mu \mathrm{V}^{2}, S D=3.99\right)$ compared to Reactive Go responses $\left(M=2.74 \mu \mathrm{V}^{2}, S D=2.74\right.$; mean difference $\left.=1.72 \mu \mathrm{V}^{2}, S E M=0.49\right), t(15)=3.46, p=$ .004, Cohen's $d_{\mathrm{z}}=0.87, B_{\mathrm{N}(0,2)}=69$. Compared to Reactive

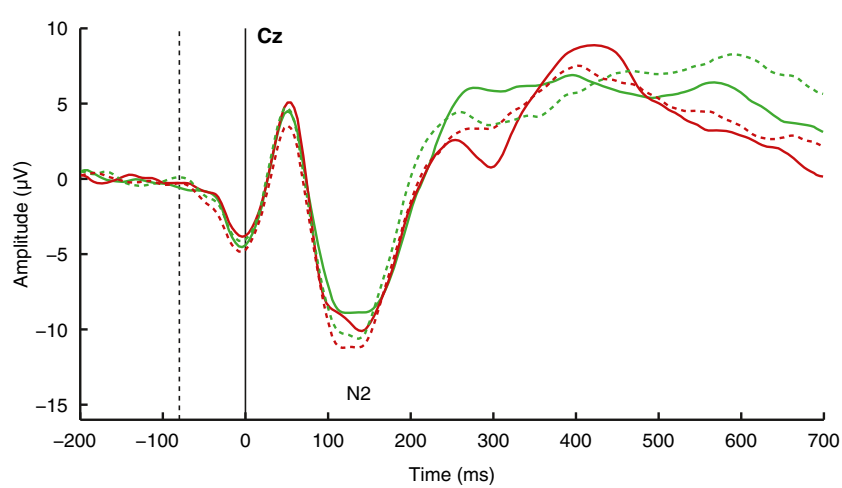

line at time $0 \mathrm{~ms}$ indicates the onset of the target and the dashed line the onset of the subliminal face prime

Go trials, FM- $\theta$ power was also larger for both Intentional Go $\left(M=4.77 \mu \mathrm{V}^{2}, S D=3.67\right.$, mean difference $=2.03 \mu \mathrm{V}^{2}, S E M$ $=0.47), t(15)=4.30, p=.001$, Cohen's $d_{\mathrm{z}}=1.08, B_{\mathrm{N}(0,2)}=$ 1367.7, and Intentional NoGo $\left(M=4.06 \mu \mathrm{V}^{2}, S D=2.99\right.$, mean difference $\left.=1.32 \mu \mathrm{V}^{2}, S E M=0.40\right), t(15)=3.31, p=$ .005, Cohen's $d_{\mathrm{z}}=0.83, B_{\mathrm{N}(0,2)}=43.1$.

Comparing mean FM- $\theta$ for Intentional Go with that for Intentional NoGo trials, there was no evidence one way or the other for an effect (mean difference $=0.71 \mu \mathrm{V}^{2}, S E M=$ $0.40), t(15)=1.76, p=.099$, Cohen's $d_{\mathrm{z}}=0.44, B_{\mathrm{N}(0,2)}=1.10$. There was also no evidence one way or the other for differences in FM- $\theta$ for Reactive NoGo trials compared to either Intentional Go (mean difference $=0.31 \mu \mathrm{V}^{2}, S E M=0.47$ ), $t(15)=0.66, p=0.517$, Cohen's $d_{\mathrm{z}}=0.76, B_{\mathrm{N}(0,2)}=0.36$, or Intentional NoGo trials (mean difference $=0.40 \mu \mathrm{V}^{2}, S E M=$ $0.65), t(15)=0.62, p=.545$, Cohen's $d_{\mathrm{z}}=0.16, B_{\mathrm{N}(0,2)}=0.47$.

Summarizing this first interaction, mean FM- $\theta$ power is significantly decreased for reactive Go trials compared to reactive NoGo and both Intentional Go and NoGo trials. These results show, first, that effortful withholding of a prepotent response in Reactive NoGo trials involves engaging cognitive control mechanisms, as indexed by increased FM- $\theta$ for Reactive NoGo trials compared to Reactive Go trials, in line with previous research (Kirmizi-Alsan et al., 2006). Furthermore, increased FM- $\theta$ for Intentional trials compared to reactive Go trials suggests that making a volitional choice 


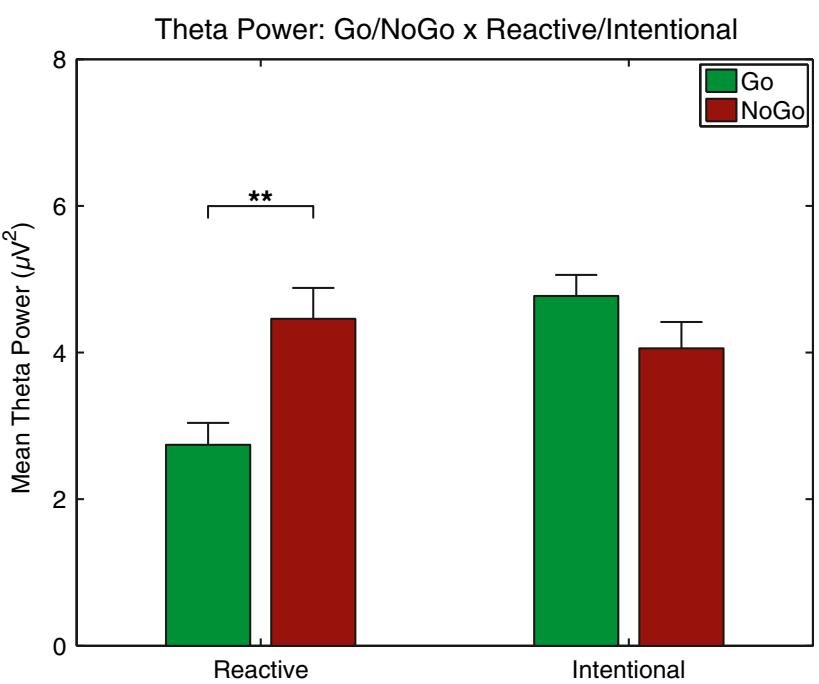

Fig. 5 Group mean FM- $\theta$ power in the Response $\times$ Response Source interaction. Error bars show within-subjects standard error following Cousineau-Morey corrections. Stars indicate results of $t$ test comparison. $* * p<.01$. No stars indicates nonsignificant comparison

between the two responses, engages cognitive control mechanisms, irrespective of the outcome. This implies, in the current paradigm, FM- $\theta$ does not only indicate exogenously elicited control, but may also be a neural signature of endogenously generated, volitional decisions about whether to execute or withhold an prepotent action, without signifying the outcome of that decision.

The second two-way interaction was between Response Source and Emotional Prime, $F(1,15)=11.94, p=.004, \eta^{2}$ $=0.44$, interaction difference $=1.42 \mu \mathrm{V}^{2}, S E M=0.41, B_{\mathrm{N}(0,2)}$ $=63.5$, illustrated in Fig. 6. Figure 7 shows the timeline of grand-average FM- $\theta$ differences (angry primes - neutral primes) over the course of a trial. Examining simple effects, there was evidence that angry primes had no effect on FM- $\theta$ in Reactive trials (mean difference $=-0.38 \mu \mathrm{V}^{2}, S E M=0.38$ ), $t(15)=-0.98, p=.341$, Cohen's $d_{\mathrm{z}}=0.25, B_{\mathrm{N}(0,2)}=0.30$. Crucially, there was an effect of angry primes on FM- $\theta$ in Intentional trials (mean difference $=1.04 \mu \mathrm{V}^{2}, S E M=0.40$ ), $t(15)=2.63, p=.019$, Cohen's $d_{\mathrm{z}}=0.65, B_{\mathrm{N}(0,2)}=5.42$, such that mean FM- $\theta$ power for Angry primes $\left(M=3.89 \mu \mathrm{V}^{2}, S D=\right.$ 3.15) was lower than that for Neutral primes $\left(M=4.93 \mu \mathrm{V}^{2}\right.$, $S D=3.53$ ). This suggests that subliminal angry faces reduce involvement of cognitive control mechanisms during Intentional trials, but not during Reactive trials, in line with the hypothesis that angry primes may influence Intentional decisions by allowing automatically inducing a withdrawal response. It was possible that the different ratio of Intentional Go to NoGo trials in response to different emotional faces could have influenced the measurements of theta power in response to different emotional faces, which could have mediated the result described here. In order to provide evidence against this, we conducted a post hoc two-way

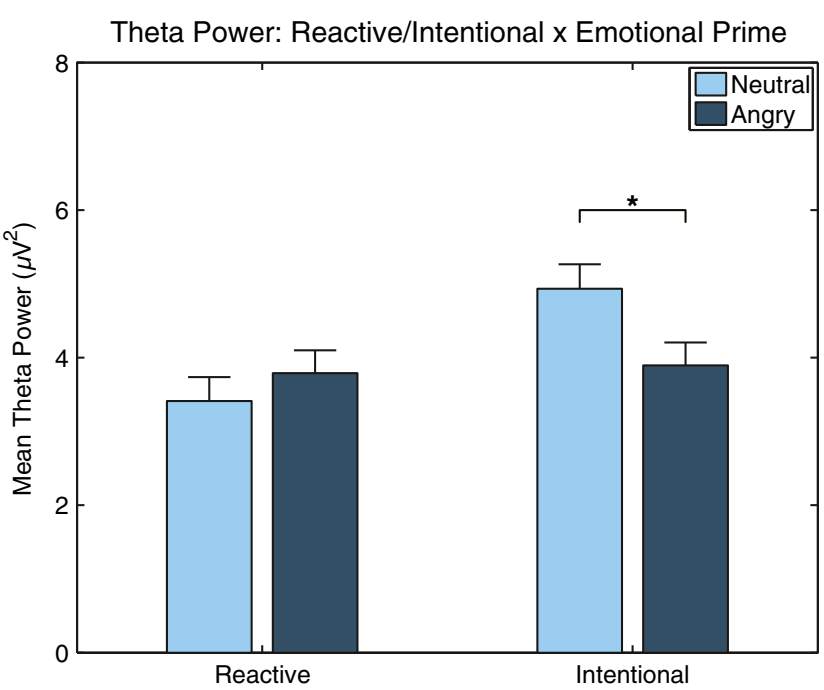

Fig. 6 Group mean FM- $\theta$ power in the Response Source $\times$ Emotional Prime interaction. Error bars show within-subjects standard error following Cousineau-Morey corrections. Stars indicate results of $t$ test comparison. $* p<.05$. No stars indicates nonsignificant comparison

ANOVA on FM- $\theta$ power for only Intentional trials, with the factors Response (Intentional Go vs. Intentional NoGo) and Emotion (neutral vs. angry). There was a main effect of emotion, as expected, $F(1,15)=6.92, p=.019$, but no significant main effect of response, $F(1,15)=3.09, p=.099$, and no significant interaction between the two factors, $F(1,15)=$ $1.94, p=.184$. This suggests that within the condition of intentional trials, the differences in theta power were driven by the effects of emotional face primes.

\section{Discussion}

Over the course of three experiments, we found that subliminally presented emotional angry faces influence intentional decisions about whether to execute or inhibit a prepotent motor action, whereas consciously perceived angry faces do not. This extends previous work showing subliminal priming of Intentional Go (Parkinson \& Haggard, 2014). Importantly, we provide novel evidence for a nonconscious mechanism influencing conscious decisions via the presentation of ecologically valid, socially salient emotional stimuli. Specifically, subliminal perception of an angry (but not neutral) face led to increased voluntary inhibition of a prepotent motor response. This finding suggests that even subliminal socially salient stimuli can engage mechanisms driving conscious (volitional) self-control. A possible explanation for this effect is that the subliminal perception of anger acts as a nonconscious cue to withdraw, rendering the subsequent volition decision to respond, or to withhold response, less voluntary. Such a mechanism would have adaptive value, whereby even fleeting or nonconscious evidence of angry individuals 


\section{Mean Frontal-Midline Theta (4-7 Hz) activity in Intentional Trials} Angry Primes - Neutral Primes

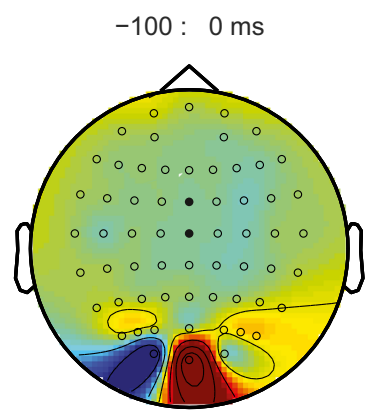

$200: 300 \mathrm{~ms}$
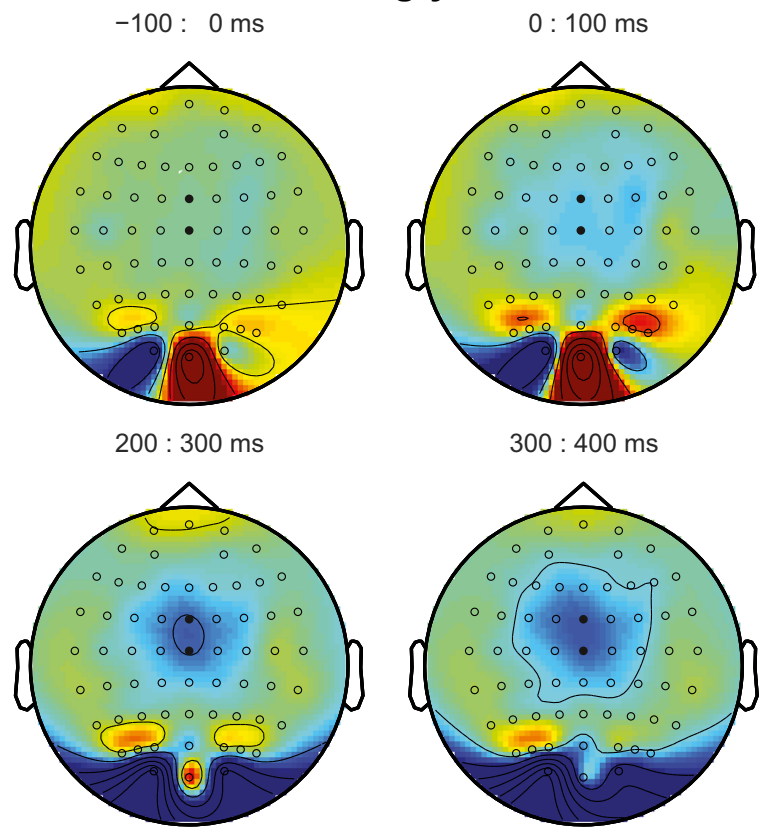

$300: 400 \mathrm{~ms}$

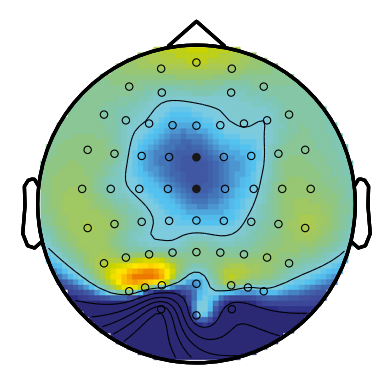

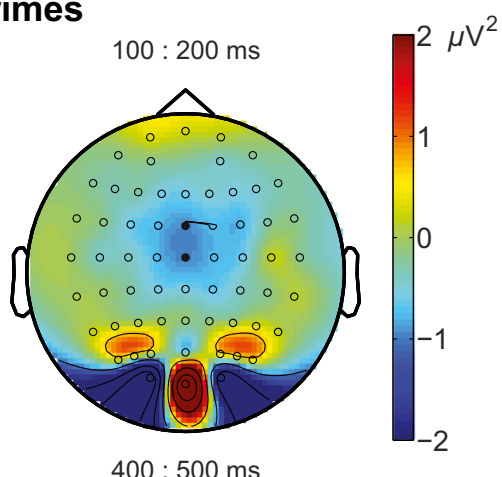

$400: 500 \mathrm{~ms}$

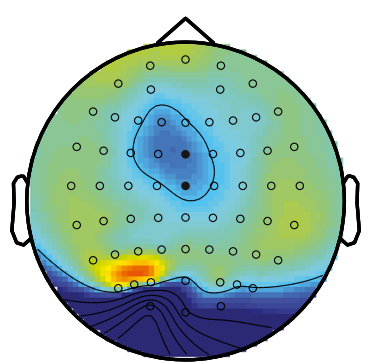

Fig. 7 Differences in mean frontal-midline theta activity (angry primes minus neutral primes) in intentional trials. Indicated times are relative to target onset. Small unfilled circles indicate electrode positions. The locations of channels $\mathrm{FCz}$ and $\mathrm{Cz}$ are highlighted as filled black circles. Frontal-midline theta is clearly lower following angry compared to neutral primes over the course of the trial. (Colour figure online) triggers a conscious process of withholding a prepotent response in order to assess the situation, to prevent any transgressive behaviour, or to avoid any further hostile, aggressive repercussions (Blair, 2003; Blair et al., 1999).

Previous research has implicated frontal-midline theta activity in exogenously cued decision making and conflict monitoring (Cavanagh et al., 2012; Kirmizi-Alsan et al., 2006), and we replicate these results, showing that FM- $\theta$ is increased for Reactive NoGo trials - when one is required exogenously to withhold a prepotent response - as compared to Reactive Go trials. Our data go further in showing that FM- $\theta$ may also act as a neural signature of endogenously generated, conscious (but rapid) decisions about whether to execute or withhold a prepotent action: FM- $\theta$ is increased for both Intentional Go and NoGo decisions (relative to Reactive Go responses). This suggests that increases in FM- $\theta$ accompany Intentional choices, but do not predict the outcome of that choice.

Crucially, our study has also shown that when making a spontaneous volitional decision to act or inhibit an action, FM- $\theta$ activity is modulated by subliminally presented emotional stimuli, such that a (subliminal) angry face leads to reduced FM- $\theta$. We propose that this reflects the angry primes' behavioural effect of predisposing an individual to withhold an action. Simply, if subliminally primed to withhold the action with an angry face and then given a volitional choice, there are reduced demands on cognitive control processes involved in making that spontaneous decision.
Several of our findings require further interpretation. First, neither experiment found significant effects of any emotional face prime on Reactive or Intentional Go response times (although the null could not be supported in all cases). This contrasts with previous studies (Parkinson \& Haggard, 2014), in which response-time effects accompanied changes in volitional choice rates: Facilitatory primes both increased choice to act and speeded Reactive and Intentional Go responses, whereas inhibitory primes reduced choice to act and slowed responses. The disparity in results is likely due to the differences in priming mechanisms utilised in these studies. Parkinson and Haggard (2014) used simple arrow stimuli as targets and subliminal primes, suggesting that priming of response rates and response times (in Intentional trials) was due to simple primetarget congruency biasing subsequent motor responses (e.g., Eimer \& Schlaghecken, 2003). This explanation can be ruled out by design in the current study, because the emotional face primes are not visually congruent with targets. Rather, we suggest that subliminal emotional faces affect intentional responses because they are salient social cues, and they exert priming effects by modulating higher-level decision-making processes (reflected by response rates but not times), not lower-level motor-response biases (reflected by response rates and response times). This is consistent with our finding that subliminal angry faces do not modulate the N2 ERP component - which is often associated with motor inhibition (Bokura et al., 2001; Eimer, 1993; Falkenstein et al., 1999; Pfefferbaum et al., 1985)_ but 
they do modulate FM- $\theta$ activity - associated with more cognitive control processes (Cavanagh \& Frank, 2014).

Second, the effects of angry faces upon intentional inhibition were only apparent when the faces were subliminally but not supraliminally presented. We suggest that this is because consciously perceived (angry) faces can be explicitly recognised as task irrelevant (given that the task is simply responding to coloured circles). Thus, participants may simply consciously discount the emotional faces. This may seem in conflict with previous research which has shown effects of emotional faces on motor inhibition (Sagaspe et al., 2011; Schulz et al., 2007); however, in such studies participants had to consciously parse the emotions of the face stimuli in order to perform the task - that is, the emotional faces were task relevant.

Third, we address our finding that the behavioural effects of subliminal emotional faces on intentional inhibition are, in the current study, specific to angry faces. One possibility is that the socially relevant information provided by an angry face is one form of threat, and, moreover, a threat directed at you, and that such stimuli have access to dedicated neural systems associated with speed and automaticity of processing. Indeed, faces, especially certain emotional faces, are a privileged class of stimuli associated with specialised neural systems (Lamy, Amunts, \& Bar-Haim, 2008; Schubö, Gendolla, Meinecke, \& Abele, 2006). Moreover, environmental cues that are threatening to the individual are afforded privileged and rapid processing via dedicated perceptual systems (LeDoux, 2003), and this processing is often automatic, bypassing cognitive processes (Ohman \& Mineka, 2001). Thus, threatening facial expressions likely have a processing advantage in terms of speed and automaticity (LeDoux, 2003). In line with this, when searching for one class of emotional face in distractor arrays of others, detection of angry faces is substantially faster (Fox et al., 2000), even when the search arrays are rendered difficult (but not subliminal) by backwards masking (Schubö et al., 2006). In addition, subliminally presented angry faces generate skin conductance responses compared to happy faces (Esteves, Dimberg, \& Öhman, 1994), indicating automatic and nonconscious threat responses. Analogously, subliminal presentation of the word ANGER can delay decision making (Garfinkel et al., 2015).

Fast subcortical neural pathways have been associated with visual perception of threatening faces, implicating the amygdala specifically in the subliminal perception of threatinducing faces, whether angry or fearful (Liddell et al., 2005; Morris, Ohman, \& Dolan, 1999; Ohman \& Mineka, 2001; Whalen et al., 1998) with visual inputs arriving via superior colliculus and pulvinar (Morris et al., 1999). This system has been likened to a "neural alarm" (Liddell et al., 2005 ) that acts as an automatic threat-detection system. Interestingly this subcortical pathway is not active when the face is consciously perceived (Morris et al., 1999).

We speculate that this mechanism is a possible candidate for mediating the nonconscious processing of subliminal angry faces as threat stimuli, leading to their effects upon intentional inhibition. Further research using functional imaging targeted at amygdala activity could explicitly test this account. However, this interpretation is not without obvious limitations. It treats angry faces as threat stimuli (directed at you) and suggests it is this threatening quality that is processed by the neural alarm system. This begs the question as to why fearful faces, also considered threat stimuli, have no measured behavioural effects in the current study. As Whalen and colleagues (1998) point out, whilst angry faces might represent a direct personal threat from a conspecific, the threat status of a fearful face can be somewhat "ambiguous in that a fearful face signals the presence of danger, but not its source" (p. 42). One reason as to why subliminal angry faces affect intentional inhibitions, but fearful faces do not, might be exactly that distinction between direct and contextual threat. Thus, much further research needs to be done to tease apart the differences between the effects of angry and fearful faces on volitional self-control. For example, the effects of fearful faces on intentional inhibition might be demonstrated by magnifying the threatening context they induce. This might be done by swiftly presenting arrays of fearful faces from which individuals unconsciously deduce a widespread threatening situation (e.g., Haberman, Harp, \& Whitney, 2009). Conversely, the effects of angry faces may be tempered by making the participants themselves no longer the target of the anger, for example, by using faces whose eye gaze or face orientation is directed away from the participants.

In summary, we have shown that volitional decisions about whether to execute or inhibit an action can be altered by taskirrelevant but socially meaningful subliminal cues, specifically, threat-evoking angry faces. Both behavioural and neural data associate this effect with high-level cognitive control rather than lowlevel motor response bias. Overall, our findings indicate that conscious decision making can be manipulated by nonconsciously perceived environmental cues, suggesting the existence of a deep-seated, ecologically tuned threat-detection system that can exert effects on volitional choices.

Acknowledgments We are grateful to the Dr. Mortimer and Theresa Sackler Foundation, which supports the Sackler Centre for Consciousness Science.

\section{Compliance with ethical standards}

Funding Information We are grateful to the Dr. Mortimer and Theresa Sackler Foundation, which supports the Sackler Centre for Consciousness Science.

Open Access This article is distributed under the terms of the Creative Commons Attribution 4.0 International License (http:// creativecommons.org/licenses/by/4.0/), which permits unrestricted use, distribution, and reproduction in any medium, provided you give appropriate credit to the original author(s) and the source, provide a link to the Creative Commons license, and indicate if changes were made. 


\section{References}

Aarts, H., Ruys, K. I., Veling, H., Renes, R. A., de Groot, J. H. B., van Nunen, A. M., \& Geertjes, S. (2010). The art of anger: Reward context turns avoidance responses to anger-related objects into approach. Psychological Science : A Journal of the American Psychological Society/APS, 21, 1406-1410.

Atas, A., Vermeiren, A., \& Cleeremans, A. (2013). Repeating a strongly masked stimulus increases priming and awareness. Consciousness and Cognition, 22(4), 1422-1430.

Baumeister, R. F., Bratslavsky, E., Muraven, M., \& Tice, D. M. (1998). Ego depletion: Is the active self a limited resource? Journal of Personality and Social Psychology, 74(5), 1252-1265.

Baumeister, R. F., Vohs, K. D., \& Tice, D. M. (2007). The strength model of self-control. Current Directions in Psychological Science, 16(6), 351-355.

Blair, R. J. R. (2003). Facial expressions, their communicatory functions and neuro-cognitive substrates. Philosophical Transactions of the Royal Society of London: Series B, Biological Sciences, 358(February), 561-572.

Blair, R. J. R., \& Cipolotti, L. (2000). Impaired social response reversal. A case of "acquired sociopathy". Brain: A Journal of Neurology, 123(Pt. 6), 1122-1141.

Blair, R. J. R., Morris, J. S., Frith, C. D., Perrett, D. I., \& Dolan, R. J. (1999). Dissociable neural responses to facial expressions of sadness and anger. Brain, 122, 883-893.

Bokura, H., Yamaguchi, S., \& Kobayashi, S. (2001). Electrophysiological correlates for response inhibition in a Go/ NoGo task. Clinical Neurophysiology: Official Journal of the International Federation of Clinical Neurophysiology, 112(12), 2224-2232.

Brainard, D. H. (1997). The Psychophysics Toolbox. Spatial Vision, 10(4), 433-436.

Bruce, V., \& Young, A. (1986). Understanding face recognition. British Journal of Psychology, 77(Pt, 3), 305-327.

Cavanagh, J. F., \& Frank, M. J. (2014). Frontal theta as a mechanism for cognitive control. Trends in Cognitive Sciences, 18(8), 414-421.

Cavanagh, J. F., Zambrano-Vazquez, L., \& Allen, J. J. B. (2012). Theta lingua franca: A common mid-frontal substrate for action monitoring processes. Psychophysiology, 49(2), 220-238.

Cousineau, D. (2005). Confidence intervals in within-subject designs: A simpler solution to Loftus and Masson's method. Tutorials in Quantitative Methods for Psychology, 1(1), 42-45.

Dehaene, S., Artiges, E., Naccache, L., Martelli, C., Viard, A., Schürhoff, F.,... Martinot, J.-L. (2003). Conscious and subliminal conflicts in normal subjects and patients with schizophrenia: the role of the anterior cingulate. Proceedings of the National Academy of Sciences of the United States of America, 100, 13722-13727.

Diamond, A. (2013). Executive functions. Annual Review of Psychology, 64, 135-168.

Dienes, Z. (2014). Using Bayes to get the most out of non-significant results. Frontiers in Psychology, 5(July), 1-17.

Eimer, M. (1993). Effects of attention and stimulus probability on ERPs in a Go/Nogo task. Biological Psychology, 35, 123-138.

Eimer, M., \& Schlaghecken, F. (2003). Response facilitation and inhibition in subliminal priming. Biological Psychology, 64(1/2), 7-26.

Esteves, F., Dimberg, U., \& Öhman, A. (1994). Automatically elicited fear: Conditioned skin conductance responses to masked facial expressions. Cognition \& Emotion, 8(5), 393-413.

Falkenstein, M., Hoormann, J., \& Hohnsbein, J. (1999). ERP components in Go/Nogo tasks and their relation to inhibition. Acta Psychologica, 101(2/3), 267-291.

Filevich, E., Kühn, S., \& Haggard, P. (2012). Negative motor phenomena in cortical stimulation: Implications for inhibitory control of human action. CORTEX, 48(10), 1251-1261.
Fox, E., Lester, V., Russo, R., Bowles, R. J., Pichler, A., \& Dutton, K. (2000). Facial expressions of emotion: Are angry faces detected more efficiently? Cognition \& Emotion, 14(1), 61-92.

Frith, C. (2009). Role of facial expressions in social interactions. Philosophical Transactions of the Royal Society of London: Series B, Biological Sciences, 364(1535), 3453-3458.

Garfinkel, S. N., Zorab, E., Navaratnam, N., Engels, M., MallorquíBagué, N., Minati, L.,... Critchley, H. D. (2015). Anger in brain and body: The neural and physiological perturbation of decisionmaking by emotion. Social Cognitive and Affective Neuroscience, (November 2014), nsv099.

Haberman, J., Harp, T., \& Whitney, D. (2009). Averaging facial expression over time. Journal of Vision, 9(11), 1.1-13.

Harrison, N. A. A., Morgan, R., \& Critchley, H. D. (2010). From facial mimicry to emotional empathy: A role for norepinephrine? Social Neuroscience, 5(March 2015), 393-400.

Hatfield, E., Cacioppo, J. T., \& Rapson, R. L. (1993). Emotional Contagion. Current Directions in Psychological Sciences, 2(808), 96-99.

Haxby, J. V., Hoffman, E. A., \& Gobbini, M. I. (2000). The distributed human neural system for face perception. Trends in Cognitive Sciences, 4(6), 223-233.

Hess, U., Adams, R. B., \& Kleck, R. E. (2009). The categorical perception of emotions and traits. Social Cognition, 27(2), 320-326.

Hommel, B. (2007). Consciousness and control. Journal of Consciousness Studies, 14(1), 155-176.

Jeffreys, H. (1939). Theory of probability. Oxford: Clarendon Press.

Jenkins, J. M., \& Ball, S. (2000). Distinguishing between negative emotions: Children's understanding of the social-regulatory aspects of emotion. Cognition \& Emotion, 14(2), 261-282.

Kirmizi-Alsan, E., Bayraktaroglu, Z., Gurvit, H., Keskin, Y. H., Emre, M., \& Demiralp, T. (2006). Comparative analysis of event-related potentials during Go/NoGo and CPT: Decomposition of electrophysiological markers of response inhibition and sustained attention. Brain Research, 1104(1), 114-128.

Kleiner, M., Brainard, D., Pelli, D., Ingling, A., Murray, R., \& Broussard, C. (2007). What's new in Psychtoolbox-3? Perception 36 ECVP Abstract Supplement, 14.

Lamy, D., Amunts, L., \& Bar-Haim, Y. (2008). Emotional priming of pop-out in visual search. Emotion, 8(2), 151-161.

Lavric, A., Pizzagalli, D. A., \& Forstmeier, S. (2004). When "go" and "nogo" are equally frequent: ERP components and cortical tomography. The European Journal of Neuroscience, 20(9), 2483-2488.

LeDoux, J. (2003). The emotional brain, fear, and the amygdala. Cellular and Molecular Neurobiology, 23(4/5), 727-738.

Libet, B., Gleason, C. A., Wright, E. W., \& Pearl, D. K. (1983). Time of conscious intention to act in relation to onset of cerebral activity (readiness-potential). Brain, 106(3), 623-642.

Liddell, B. J., Brown, K. J., Kemp, A. H., Barton, M. J., Das, P., Peduto, A.,... Williams, L. M. (2005). A direct brainstem-amygdala-cortical "alarm" system for subliminal signals of fear. NeuroImage, 24(1), 235-243.

Logan, G. D., \& Cowan, W. B. (1984). On the ability to inhibit thought and action: A theory of an act of control. Psychological Review, 91(3), 295-327.

Lyman, P., \& Averill, J. R. (1982). Anger and aggression: An essay on emotion. New York: Springer-Verlag.

Marsh, A. A., Ambady, N., \& Kleck, R. E. (2005). The effects of fear and anger facial expressions on approach- and avoidance-related behaviors. Emotion, 5(1), 119-124.

Mayr, U. (2004). Conflict, consciousness, and control. Trends in Cognitive Sciences, 8(4), 145-148.

Morey, R. D. (2008). Confidence intervals from normalised data: A correction to Cousinea (2005). Tutorial in Quantitative Methods for Psychology, 4(2), 61-64. 
Morris, J. S., Ohman, A., \& Dolan, R. J. (1999). A subcortical pathway to the right amygdala mediating "unseen" fear. Proceedings of the National Academy of Sciences of the United States of America, 96(4), 1680-1685.

Nigg, J. T., Butler, K. M., Huang-Pollock, C. L., \& Henderson, J. M. (2002). Inhibitory processes in adults with persistent childhood onset ADHD. Journal of Consulting and Clinical Psychology, 70(1), 153-157.

O'Brien, F., \& Cousineau, D. (2015). Representing error bars in withinsubject designs in typical software packages. Tutorials in Quantitative Methods for Psychology, 11(2), 126-126.

Ohman, A., \& Mineka, S. (2001). Fears, phobias, and preparedness: toward an evolved module of fear and fear learning. Psychological Review, 108(3), 483-522.

Oostenveld, R., Fries, P., Maris, E., \& Schoffelen, J. M. (2011). FieldTrip: Open source software for advanced analysis of MEG, EEG, and invasive electrophysiological data. Computational Intelligence and Neuroscience. doi:10.1155/2011/156869

Parkinson, J., \& Haggard, P. (2014). Subliminal priming of intentional inhibition. Cognition, 130(2), 255-265.

Parkinson, J., \& Haggard, P. (2015). Choosing to stop: Responses evoked by externally triggered and internally generated inhibition identify a neural mechanism of will. Journal of Cognitive Neuroscience, 27(10), 1948-1956.

Peters, M. A., \& Lau, H. C. (2015). Human observers have optimal introspective access to perceptual processes even for visually masked stimuli. eLife. doi:10.7554/eL

Pfefferbaum, A., Ford, J. M., Weller, B. J., \& Kopell, B. S. (1985). ERPs to response production and inhibition. Electroencephalography and Clinical Neurophysiology, 60(5), 423-434.

Sagaspe, P., Schwartz, S., \& Vuilleumier, P. (2011). Fear and stop: A role for the amygdala in motor inhibition by emotional signals. NeuroImage, 55(4), 1825-1835.

Schubö, A., Gendolla, G. H. E., Meinecke, C., \& Abele, A. E. (2006). Detecting emotional faces and features in a visual search paradigm: Are faces special? Emotion, 6(2), 246-256.

Schulz, K. P., Fan, J., Magidina, O., Marks, D. J., Hahn, B., \& Halperin, J. M. (2007). Does the emotional go/no-go task really measure behavioral inhibition? Convergence with measures on a nonemotional analog. Archives of Clinical Neuropsychology, 22, 151160.

Shadlen, M. N., \& Gold, J. I. (2004). The neurophysiology of decisionmaking as a window on cognition BT-The cognitive neurosciences. In M. S. Gazzaniga (Ed.), The cognitive neurosciences (pp. 1229-1241). Cambridge: MIT Press.

Sherman, D. K., Cohen, G. L., Nelson, L. D., Nussbaum, A. D., Bunyan, D. P., \& Garcia, J. (2009). Affirmed yet unaware: Exploring the role of awareness in the process of self-affirmation. Journal of Personality and Social Psychology, 97(5), 745-764.

Szczepanowski, R., \& Pessoa, L. (2007). Fear perception: Can objective and subjective awareness measures be dissociated? Journal of Vision, 7(4), 10.

van Gaal, S., Ridderinkhof, K. R., van den Wildenberg, W. P. M., \& Lamme, V. A. F. (2009). Dissociating consciousness from inhibitory control: Evidence for unconsciously triggered response inhibition in the stop-signal task. Journal of Experimental Psychology: Human Perception and Performance, 35(4), 1129-1139.

van Gaal, S., Lamme, V. A. F., Fahrenfort, J. J., \& Ridderinkhof, K. R. (2011). Dissociable brain mechanisms underlying the conscious and unconscious control of behavior. Journal of Cognitive Neuroscience, 23(1), 91-105.

Veling, H., Aarts, H., \& Stroebe, W. (2011). Fear signals inhibit impulsive behavior toward rewarding food objects. Appetite, 56(3), 643-648.

Verbruggen, F., \& Logan, G. D. (2008). Response inhibition in the stopsignal paradigm. Trends in Cognitive Sciences, 12(11), 418-424.

Whalen, P. J., Rauch, S. L., Etcoff, N. L., McInerney, S. C., Lee, M. B., \& Jenike, M. A. (1998). Masked presentations of emotional facial expressions modulate amygdala activity without explicit knowledge. The Journal of Neuroscience: The Official Journal of the Society for Neuroscience, 18(1), 411-418.

Willenbockel, V., Sadr, J., Fiset, D., Horne, G., Gosselin, F., \& Tanaka, J. (2010). The SHINE toolbox for controlling low-level image properties [Abstract]. Journal of Vision, 10(7), 653.

Yik, M. S. M. (1999). Interpretation of faces: A cross-cultural study of a prediction from Fridlund's theory. Cognition \& Emotion, 13(March 2015), 93-104. 